\title{
SATELLITE-DERIVED BATHYMETRY USING RANDOM FOREST ALGORITHM AND WORLDVIEW-2 IMAGERY
}

\author{
M. D. M. Manessa a, b, A. Kanno a, M. Sekine a, M. Haidar ${ }^{\text {c, }}$ K. Yamamoto a , T. Imai ${ }^{\text {a }}$, T. Higuchi ${ }^{\text {a }}$ \\ a Graduate School of Science and Engineering, Yamaguchi University, Ube, Japan \\ ${ }^{b}$ Center for Remote Sensing and Ocean Science (CReSOS), Udayana University, Indonesia \\ ${ }^{c}$ Center for Thematic Mapping and Integration, Geospatial Information Agency, Indonesia
}

\section{Article Info:}

Received: 11 August 2016 in revised form: 18 September 2016

Accepted: 19 September 2016

Available Online: 31 October 2016

\section{Keywords:}

Satellite-derived bathymetry, Worldview-2, random forest, multiple linear regression

\section{Corresponding Author:}

Masita Dwi Mandini Manessa

Graduate School of Science and

Engineering, Yamaguchi University,

Ube, Japan

Email:

masita@yucivil.onmicrosoft.com
Abstract: In empirical approach, the satellite-derived bathymetry (SDB) is usually derived from a linear regression. However, the depth variable in surface reflectance has a more complex relation. In this paper, a methodology was introduced using a nonlinear regression of Random Forest (RF) algorithm for SDB in shallow coral reef water. Worldview-2 satellite images and water depth measurement samples using single beam echo sounder were utilized. Furthermore, the surface reflectance of six visible bands and their logarithms were used as an input in RF and then compared with conventional methods of Multiple Linear Regression (MLR) at ten times cross validation. Moreover, the performance of each possible pair from six visible bands was also tested. Then, the estimated depth from two methods and each possible pairs were evaluated in two sites in Indonesia: Gili Mantra Island and Panggang Island, using the measured bathymetry data. As a result, for the case of all bands used the RF in compared with MLR showed better fitting ensemble, -0.14 and $-1.27 \mathrm{~m}$ of RMSE and 0.16 and 0.47 of $R^{2}$ improvement for Gili Mantra Islands and Panggang Island, respectively. Therefore, the RF algorithm demonstrated better performance and accuracy compared with the conventional method. While for best pair identification, all bands pair wound did not give the best result. Surprisingly, the usage of green, yellow, and red bands showed good water depth estimation accuracy.

Copyright (C) 2016 GJGP-UNDIP This open access article is distributed under a Creative Commons Attribution (CC-BY-NC-SA) 4.0 International license.

How to cite (APA 6th Style):

Manessa, M. D. M, et al. (2016). Satellite-derived bathymetry using random forest algorithm and worldview-2 imagery. Geoplanning: Journal of Geomatics and Planning, 3(2), 117-126. doi:10.14710/geoplanning.3.2.117-126

\section{INTRODUCTION}

Due to the limitation of costly and time-consuming bathymetry measurement, getting a dense or full coverage water depth data is difficult to achieve. Satellite derived bathymetry (SDB) is useful to efficiently densify (depend on image spatial resolution) the information of water depth in shallow water areas. In the case of a multispectral image, there are simple and applicable SDB methods such as linear regression of reflectance logarithm (Lyzenga, Malinas, \& Tanis, 2006; Lyzenga, 1978; Paredes \& Spero, 1983), the linear ratio (Stumpf, Holderied, \& Sinclair, 2003), and Depth of Penetration Zone (Jupp, 1988). At the current state, the linear regression is the most common and widely used SDB (Flener et al., 2012; Kanno \& Tanaka, 2012; Liceaga-Correa \& Euan-Avila, 2002; Yuzugullu \& Aksoy, 2014).

Unfortunately, Stumpf et al. (2003) showed a low accuracy estimation of SDB method using linear regression. The problem might be caused by the assumption of a linear relation between depth and water surface reflectance that sometimes does not hold. Especially when the following conditions exist: noisy satellite image, the dark bottom object in shallow water or vice versa, and high water attenuation. Nonlinear regression approach seems promising to improve the SDB accuracy. The non-linear regression of random forest (RF) algorithm shows a good performance in estimating a variable with non-linear condition (Knudby et al., 2013). 
The multispectral image used in this study is the high spatial resolution image of Worldview-2 (WV-2) imagery. Several studies, for instances Kerr (2011), Lee et al. (2011), Doxani et al. (2012), and Eugenio, Marcello, \& Martin (2015), have been carried out on SDB using WV-2 imagery. Since WV-2 imagery has six visible bands then choosing the right band combination for SDB was also important. Kerr (2011) has revealed the best pair of WV-2 bands for the combination of linear ratio and MLR method. However, identifying the best pair for the linear reflectance and Random Forest algorithm for SBD was never done before.

This study examined the usage of RF algorithm for SDB. As a comparison, the confessional SDB method using multiple linear regression (MLR) algorithms for multiple bands were analyzed. The accuracy change between both algorithms shows the performance of linear and nonlinear regression for SDB. Additionally, 63 possible pairs from six visible bands of the WV-2 image was equally tested as an input for RF algorithm to identify the best pair band for SDB using RF algorithm.

\section{DATA AND METHODS}

\subsection{Study Sites}

As shown in Figure 1, the study site was a shallow coral reef environment located in Indonesia. The Gili Mantra Islands is off the Coast of Lombok Island, and the Panggang Island is at north part of Jakarta Coast. The Gili Matra Islands are a Marine Natural Park including three islands: Gili Trawangan, Gili Meno, and Gili Air. Both sites are coral reef environment with clear water and good visibility.

Figure 1. a. Panggang Island Worldview2 true-colour image (RGB 532); and b. Gili Mantra Islands Worldview2 true-colour image (RGB 532) (Digital Globe, 2012)
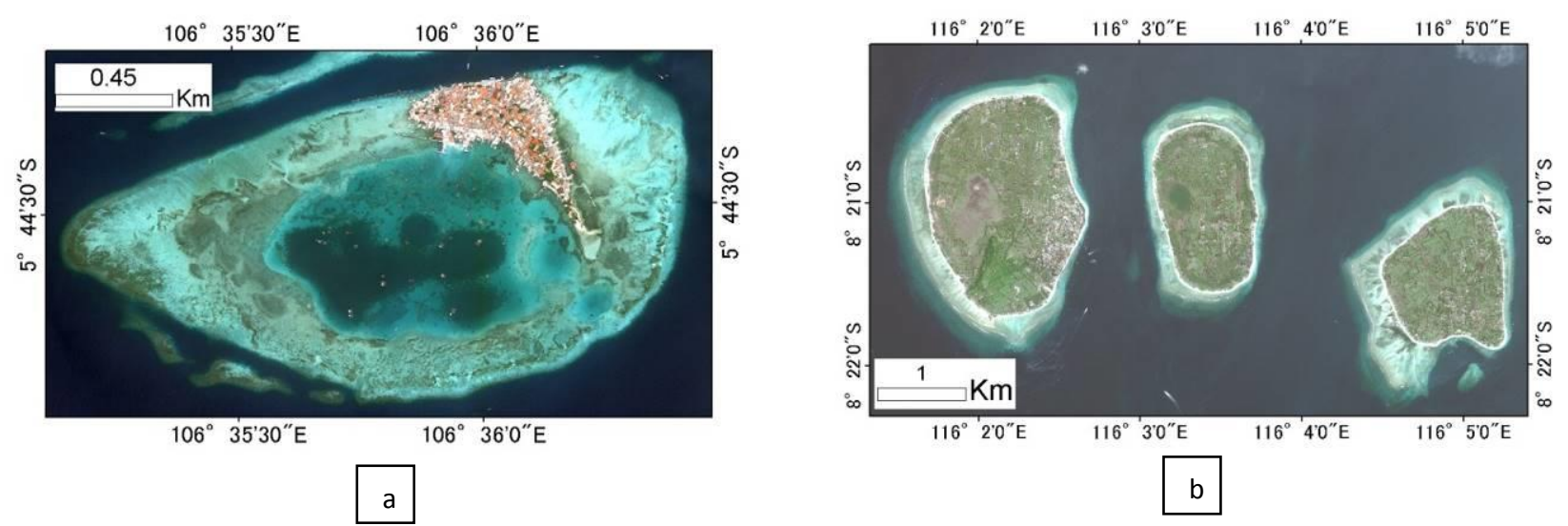

\subsection{Depth measurement data}

The bathymetry data of the Gili Islands were resulted from a collaborative effort between CReSOS (Center for Remote Sensing and Ocean Science, Udayana University-JAXA program), Yamaguchi University, and the Research Institute for Marine Research and Observation (Ministry of Marine Affairs and Fisheries Republic of Indonesia). While for Panggang Island, the data were measured by Center for Thematic Mapping and Integration, Geospatial Information Agency of Indonesia, Indonesia. For both sites, the measurement was carried out using a single beam echo sounder and Differential Global Positioning System (D-GPS). Since the depth measurement data was tide affected, the measurement depth was necessarily referred to mean sea levels (MSL). The converter was done by subtracting the measurement depth with at time tide. Moreover, the tidal data were collected from nearest tidal station.

\subsection{Image acquisition and processing}

In this study, the level 2 radiometric corrected of WorldView-2 imagery with six visible bands and two near-infrared bands were utilized. The imagery passed three steps of image pre-processing. The first step was sensor calibration from digital numbers to the units of band-averaged spectral reflectance or TOA (top of atmosphere) reflectance. The equations and calibration coefficients applied were based on the Digital Globe technical note about the radiometric use of WorldView-2 imagery (Digital Globe, 2012). The physical 
units of band-averaged spectral radiance are $\mathrm{W} \cdot \mathrm{m}^{-2} \cdot \mathrm{sr}^{-1} \cdot \mu \mathrm{m}^{-1}$. Secondly, the atmospheric and surface noise then TOA reflectance were corrected by applying Lyzenga et al.'s (2006) correction. Then, the formula of Lyzenga et al.'s (2006) atmospheric correction is written as:

$\rho_{\text {clly }}=\rho_{\text {TOA }}-\alpha_{i N I R 1} \cdot\left(\rho_{\text {TOANIR } 1}-\bar{\rho}_{\text {TOANIR1 }}\right)-\alpha_{\text {iNIR } 2} \cdot\left(\rho_{\text {TOA.NIR2 }}-\bar{\rho}_{\text {TOA.NIR } 2}\right)$

Where $\rho_{\text {TOANIR1 }}$ is the measured TOA reflectance in NIR 1 band, $\bar{\rho}_{\text {TOA.NIR1 }}$ is that average over the deep water pixels, and $\alpha_{i N I R n}$ is the slope of the simple regression line between the visible reflectance and NIR 1 reflectance for the deep-water pixels. While $\alpha_{\text {iNIR2 }}, \rho_{\text {TOA.NIR } 2}, \bar{\rho}_{\text {TOA.NIR2 }}$ is for NIR 2 .

Lastly, the relationship between radiance and depth was linearized to create the transformed reflectance $\left(X_{i}\right)$. Based on Lyzenga et al. (2006), the transformed reflectance $\left(X_{i}\right)$ is a linear value of reflectance and depth and written as:

$X_{i}=\log \left(\rho_{s_{i}}-\bar{\rho}_{s_{\infty, i}}\right)$

Where $\overline{\rho_{s}} \infty_{i}$ is the mean of surface reflectance deep water area for each band $i$. The $X_{i}$ for six visible bands are used as on input for MLR and RF regression model.

\subsection{Prediction Models}

\subsubsection{Random Forest (RF)}

Random forests for nonlinear regression are formed by growing trees depending on a random vector such that the tree predictor takes on numerical values as opposed to class labels (Breiman, 2001). This nonlinear regression is a machine learning approach that belongs to the family of decision tree learning (Breiman, 2001). The goal of decision tree learning is to create a model that predicts the value of a target variable based on several input variables (Diesing et al., 2014). For estimating the water depth, the "random forest" function from random forest package of $\mathrm{R}$ software was used.

\subsubsection{Multiple Linear Regression (MLR)}

The multiple linear regression is (Lyzenga et al., 2006). The MLR analysis was conducted to depth as the dependent variable and the $X_{i}$ as the independent variables. Then depth estimation formula for WorldView-2 imagery with six visible bands is as follows:

$\hat{h}=\beta_{0}-\sum_{i=1}^{\mathrm{n}} \beta_{\mathrm{i}} \cdot X_{\hat{\mathrm{i}}}$

where $\beta_{0}$ is offset, $\beta_{i}$ is determined by a linear regression analysis using a set of depths measured with the linearized surface reflectance and $n$ is a number of the band. In the case of MLR analysis, the water depth estimation is predicted using the "Im" function from basic package in R software.

\subsection{Band Pair or Combination}

Since WV2 have six visible bands, 63 different pairs ( $=6$ combinations one band +15 combinations of two bands +20 combinations of three bands +15 combinations of four bands +6 combinations of five bands +1 combination six bands) could be used as an input for Eq. 3. We tested the performance of each pair to estimate the water depth using RF formula (see Figure 2). 
Figure 2. Worldview-2 Image: a. Panggang Islands Image before correction, b. Panggang Islands Image after correction, c. Gili Mantra Islands Image before correction, d. Gili Mantra Islands Image after correction. (Analysis, 2016)
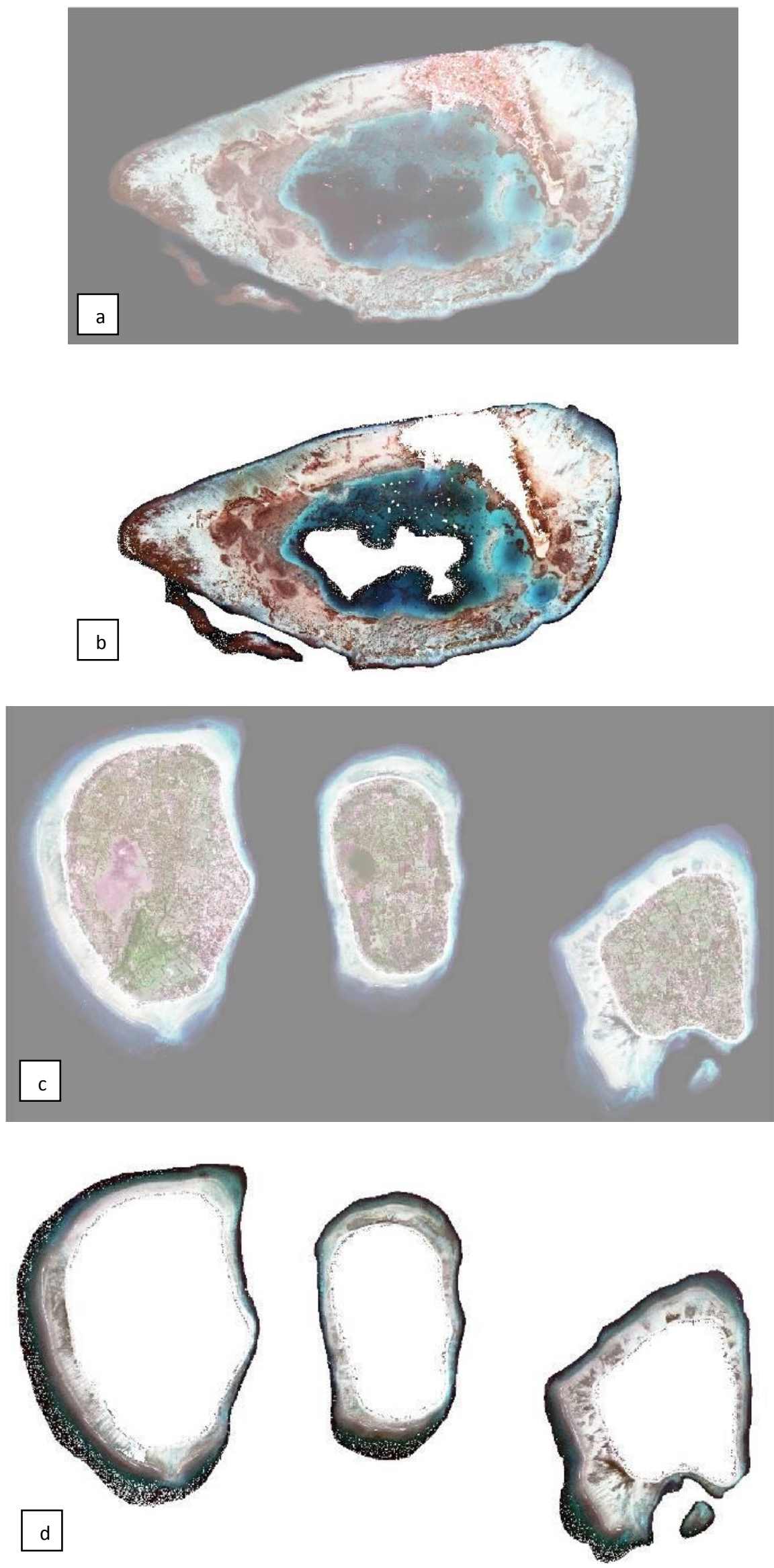


\subsection{Cross Validation}

In order to further test the efficiency of each model, a cross-validation experiment was performed. In each round, the depth measured points were randomly selected, with $10 \%$ used as training data and $90 \%$ as test data. This cross-validation procedure was repeated 100 times. For each run, the model prediction accuracy were evaluated using two statistical key that explain in subsection 2.7.

\subsection{Model Validation}

The depth estimation accuracy of each model is measured by:

$\mathrm{R}^{2}=1-\sum_{\hat{i}}\left(h_{\hat{i}}-\hat{h}_{i}\right)^{2} / \sum_{\hat{i}}\left(h_{\hat{i}}-\bar{h}\right)^{2}$

$\operatorname{RMSE}=\left(\sum_{i=1}^{n}\left(h_{i}-\hat{h}_{i}\right)^{2} / n\right)^{0.5}$

Where $h$ is measurement depth, $\hat{h}$ is estimated depth, $\bar{h}$ is the mean of depth measurement value, and $n$ is the number of input data.

\section{RESULTS AND DISCUSSION}

\subsection{Image Correction}

Lyzenga et al.'s (2006) image correction was applied to the evaluated Worldview-2 images of Gili Mantra Islands and Panggang Island. The NIR band was used to remove the noise from sea surface and atmospheric. Since the Worldview-2 have two NIR bands, both of them bands was used in this study as shown in Equation 1. Figure 2 shows the image of before and after correction. Besides correcting the image noise, this method also masks the depth and land areas, as shown in Figure $\mathbf{2 b}$ for Panggang Island and Figure 2d for Gili Mantra Islands.

Figure 3. Scatterplot of estimate depth versus actual depth for RF and MLR algorithm in Gili Mantra Island and Panggang Island. The red line axis is line of $y=x$. (Analysis, 2016)

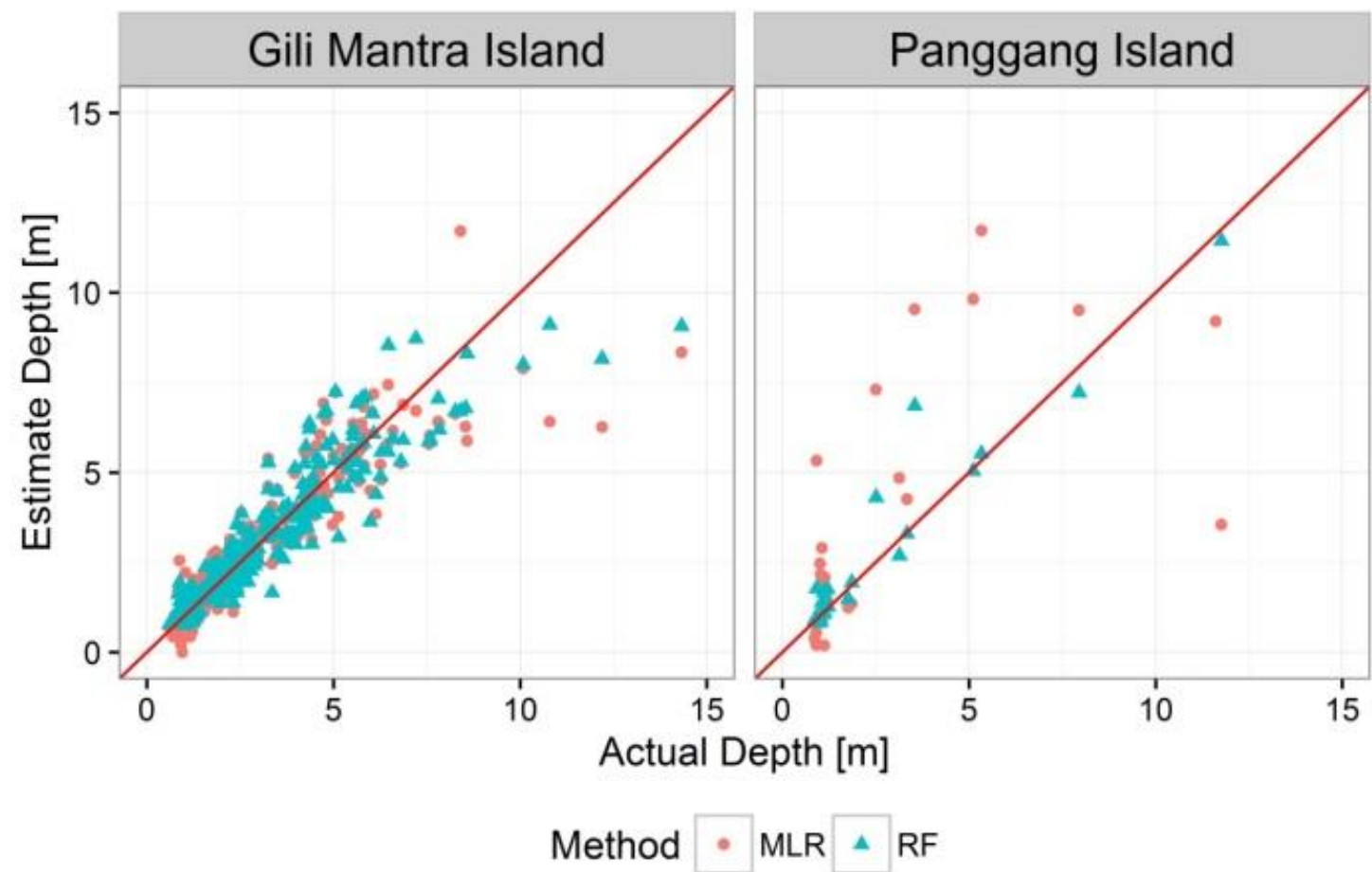


Figure 4. Graph of Statistic value of RMSE and $R^{2}$ for RF and MLR algorithm in Gili Mantra Island and Panggang Island (Analysis, 2016)

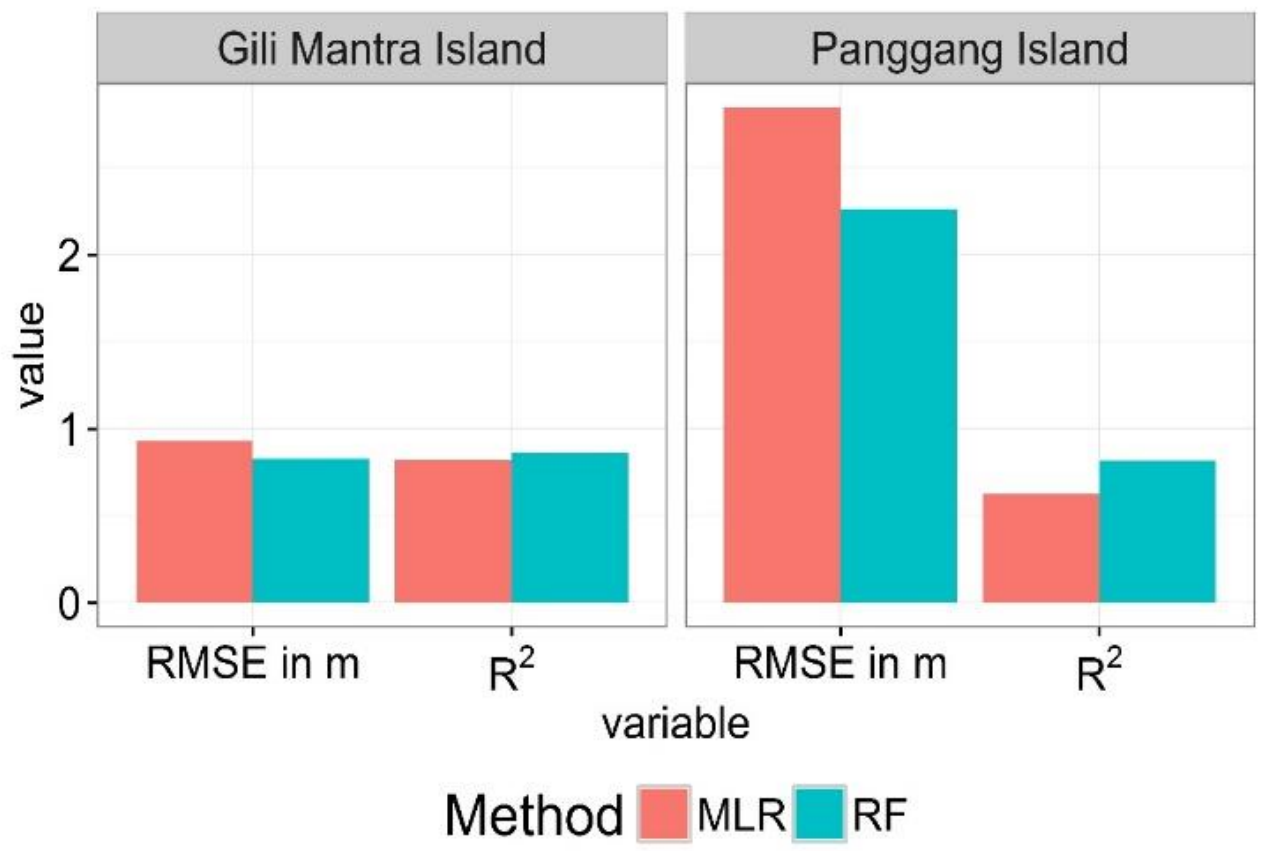

\subsection{Random forest (RF) algorithm for SDB}

Figure 3 shows the result of the SDB performance for the RF compared with MLR algorithm in Gili Mantra Islands and Panggang Islands. In general, the estimation of depth shows better fitting in the shallow area with depth less than $\pm 7 \mathrm{~m}$ then gradually increase following the increse water depth. The higher error in deeper depth mainly occurred because of high noise in the deeper water generated by the high absorption and scattering of light, and as explain by Stumpf et al. (2003).

In Figure 4, a statistical evaluation was carried out to qualitatively measure the performance of RF in compared with MLR algorithm. As a result, the error created from RF algorithm is smaller than MLR algorithm for the both evaluated sites. The RF algorithm for depth estimation accuracy is more accurate with less error with -0.14 and $-1.27 \mathrm{~m}$ of lower RMSE and better fitting of 0.16 and 0.47 of $\mathrm{R}^{2}$ improvement for Gili Mantra Islands and Panggang Island, respectively. This result has further strengthened our conviction that in some case the depth had a complex's relation with reflectance.

Theoretically, the relation between depths and linearize surface reflectance should be linear but a noise could cause a non-linear condition (Lyzenga, 1978). Referring to the Gili Mantra Islands and Panggang Islands Site, the plotted value (Figure 5) between depths and linearize surface reflectance shows unlinearity relations, where the relationship became scatter following the increases depth. The scatters relation in the deeper water areas because of reflectance or radiance received by multispectral satellite contain higher percentage of noise than bottom reflectance information due to high absorption and scattering. Then, it has limited the maximum detected depth of multispectral SDB. This un-linear relation factor is potentially responsible for this different performance in both sites. Moreover, in Panggang Island, the pixels in different depth had almost the same value that might be caused by dark object in shallow depth or bright object in deeper depth. This fact became the main reason of poor estimation in Panggang Island. 
Figure 5. The relation between depth and linearize surface reflectance for each band in Gili Mantra Island and Panggang Island (Analysis, 2016)
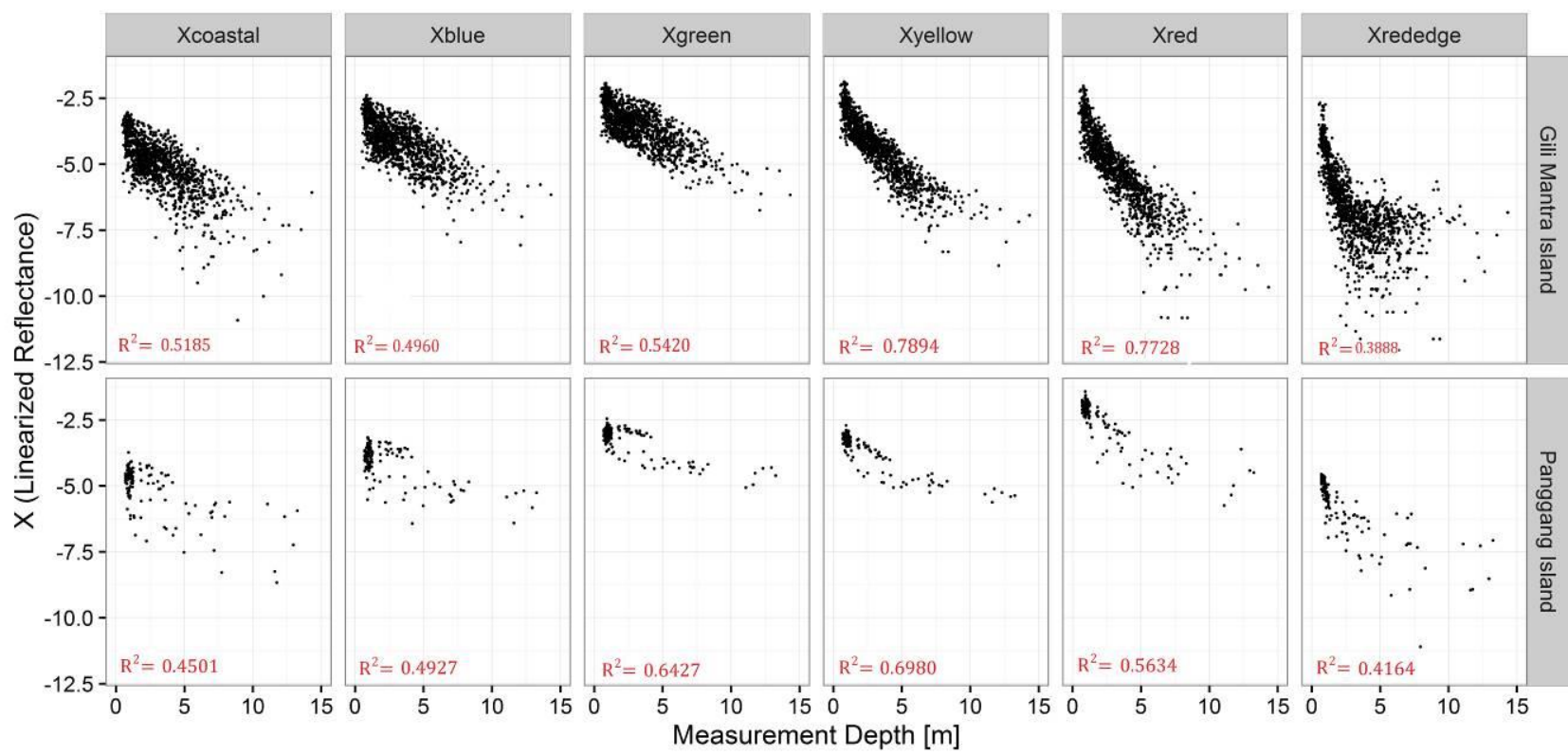

\subsection{Best combination bands of Random Forest (RF) algorithm for SDB}

Figure 6 shows the performance of RF algorithm under 63 possible combinations of Worldview-2 bands for both sites. As a result, the rank of the best pair is varied between Gili Mantra Islands and Panggang Island. Thus, this result needs to be interpreted with caution as a following. Firstly, the SDB accuracy ranges between $0.746-1.779 \mathrm{~m}$ and $0.350-0.874$ for RMSE and $\mathrm{R}^{2}$, respectively, in the case of Gili Mantra Island. While for Panggang Islands, the accuracy varies between $1.747-3.712$ and $0.354-$ 0.858 for RMSE and $R^{2}$, respectively. Secondly, in contrast with the previous study (Kerr, 2011), the best performance of RF was not given by the usage of all the visible bands. In the case of Gili Mantra Island, the best accuracy was achieved when four bands of coral, green, yellow and red (14.CGYR) were used. While Panggang Island site shows the best accuracy using three bands of green, yellow and red (39.GYR). Although six visible bands of WV-2 were expected to estimate the depth accurately, it was not predicted that the six bands would also give the best accuracy compared with less number of bands as an input. This is not particularly unexpected considering that some bands contain more noise or less bottom reflectance information than other, such as Red Edge bands having less bottom reflection information especially in the deeper depth due to high absorption value.

Interestingly, for both evaluated sites the usage of band green, yellow, and red shows better estimation accuracy. Meanwhile, the other bands namely coastal, blue, and rededge had a tendency to give the adverse effect of poor estimation accuracy. As shown in Figure 5, even though the short wavelength namely coastal and blue band are sensitive to water depth and penetrate into the deeper water, the high noise is also included. This problem is an issue of WV-2 coastal band that claims to be useful for shallowwater mapping. 
Figure 6. Graph of SDB estimation accuracy of RF algorithm of 63 combination bands. (Left) Gili Mantra Island and (right) Panggang Islands (Analysis, 2016)
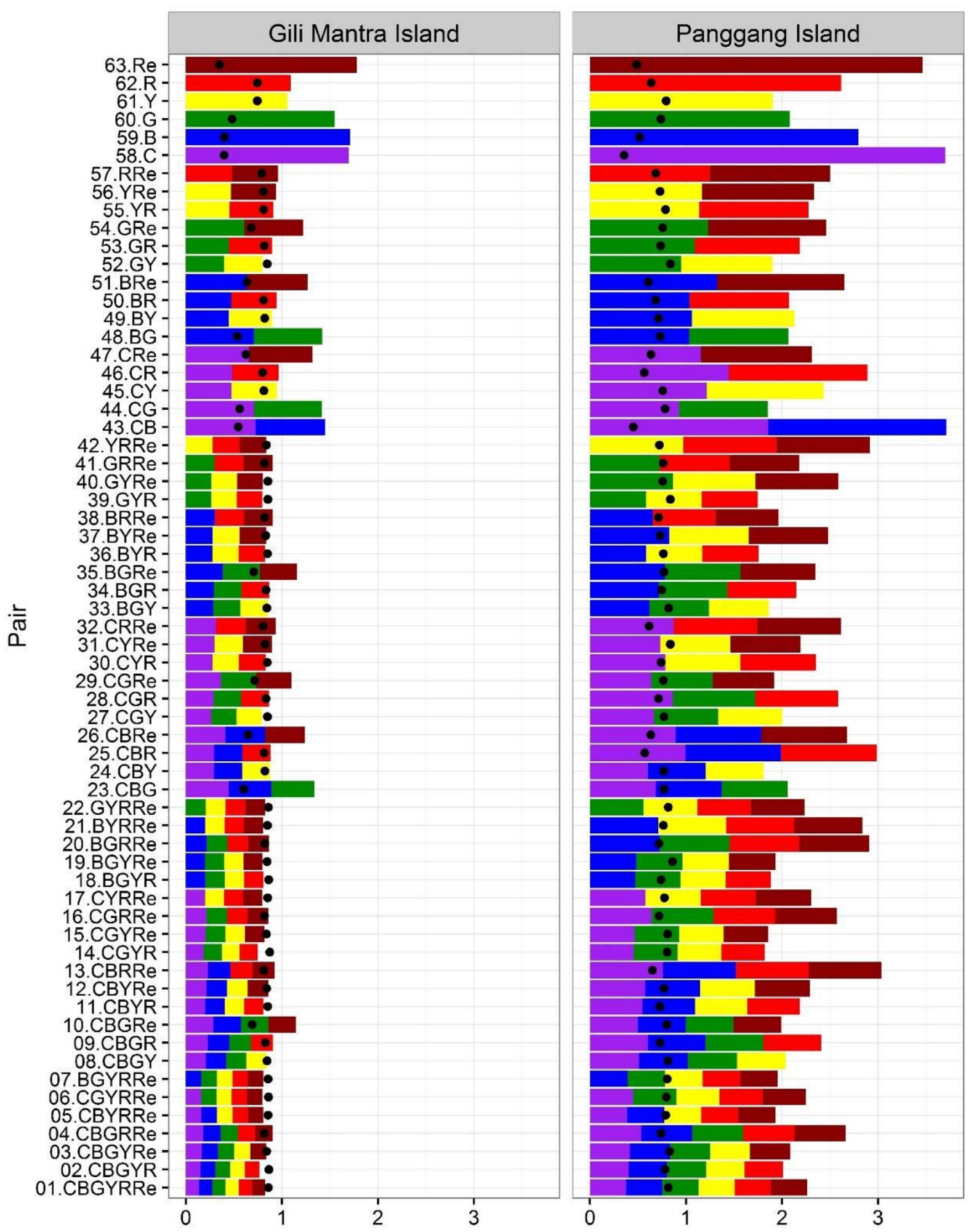

Bar Graph : RMSE in meter

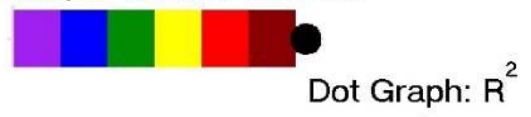

Bar Graph Legend

\begin{tabular}{lll}
\hline Coastal & Green \\
Blue & Yellow & Red \\
& RedEdge
\end{tabular}

The color bar is the RMSR in meter, and black dot is $\mathrm{R}^{2}$. Example: 01.CBYGRRed is combination number 1 consisting of Coral, Blue, Yellow, Green, Red, and Red Edge bands, for Gili Islands the RMSR is $0.8 \mathrm{~m}$ and $\mathrm{R}^{2}$ is 0.9 . 
It is worth noting that this study has a few limitations. The first is a time gap between measurement and image recording dates; some morphological change might appear in the shallow water areas. The second is error created from measurement instrument; the single beam echo sounder generates error caused by inaccurate of average sound speed measurement, especially due to rapid movement of the boat or extreme morphological changes. Then, the measurement data on deeper depth will tend to have a high error. Thirdly, in the application of random forest algorithm, three hyper-parameters, i.e., $m_{\text {try, }}$ sampling size, and node size should be optimized. Moreover, the random forest function (Random Forest package of $R$ software) used in this study has an auto-tuning capability for $m_{\text {try, }}$ but it does not consistently work well. Further works need to be performed to do the manual optimization.

\section{CONCLUSION}

In this study, non-linear model of Random Forest (RF) regression was tested to estimate the water depth of shallow coral reef. Also, the linear model of Multiple Linear Regression (MLR) was used for comparison. A cross-validation test comparing the accuracy of the both algorithms was performed for two coral reef sites of Gili Mantra Islands and Panggang Island using WorldView-2 (WV-2) imagery and corresponding insitu depth measurements. Considering the six visible bands of WV-2 images, 63 possible pairs were evaluated to identify the best pair as an input in estimating the water depth using Random Forest algorithm.

The result of this study indicates that the nonlinear regression (RF) performed better than linear regression (MLR) in estimating the water depth. The RF regression is suitable for multispectral-based SDB, especially, when the relation between depth and linearized reflectance was far from linear due to the noisy image. Moreover, the best RF model for SDB was set when Green, Yellow, and Red bands have been utilized. This study only tested two sites with water in clear visibility. Subsequently, the RF performance for the different type of water might show a different result. Further studies, which take more sites into account, are suggested.

\section{ACKNOWLEDGMENTS}

The authors acknowledge support from the Indonesia Endowment Fund for Education (LPDP) by the Ministry of Finance. We would like to thank the Geospatial Information Agency of Indonesia for providing the Gili Mantra Islands' as well as Panggang Island's bathymetry and tidal data. This research was partially supported by a research grant of Kurita Water and Environment Foundation (No. 15B013).

\section{REFERENCES}

Breiman, L. (2001). Random forests. Machine Learning, 45(1), 5-32.

Diesing, M., et al. (2014). Mapping seabed sediments: Comparison of manual, geostatistical, object-based image analysis and machine learning approaches. Continental Shelf Research, 84, 107-119.

Digital Globe. (2012). Radiometric Use of WorldView-2 Imagery. Available online: http://www.digitalglobe.com/downloads/Radiometric_Use_of_WorldView-2_Imagery.pdf

Doxani, G., et al. (2012). Shallow-water bathymetry over variable bottom types using multispectral Worldview-2 image. International Archives of the Photogrammetry, Remote Sensing and Spatial Information Sciences, 39(8), 159-164.

Eugenio, F., Marcello, J., \& Martin, J. (2015). High-resolution maps of bathymetry and benthic habitats in shallow-water environments using multispectral remote sensing imagery. IEEE Transactions on Geoscience and Remote Sensing, 53(7), 3539-3549.

Flener, C., et al. (2012). Comparison of empirical and theoretical remote sensing based bathymetry models in river environments. River Research and Applications, 28(1), 118-133.

Jupp, D. L. B. (1988). Background and extensions to depth of penetration (DOP) mapping in shallow coastal waters. In Proceedings of the Symposium on Remote Sensing of the Coastal Zone (p. IV--2).

Kanno, A., \& Tanaka, Y. (2012). Modified Lyzenga's method for estimating generalized coefficients of satellite-based predictor of shallow water depth. IEEE Geoscience and Remote Sensing Letters, 9(4), 715-719.

Kerr, J. M. (2011). Worldview-02 offers new capabilities for the monitoring of threatened coral reefs. In Proceedings of the Geospatial World Forum. 
Knudby, A., et al. (2013). Mapping Coral Reef Resilience Indicators Using Field and Remotely Sensed Data. Remote Sensing, 5(3), 1311-1334. http://doi.org/10.3390/rs5031311

Lee, K. R., et al. (2011). Determination of bottom-type and bathymetry using WorldView-2. Proc. SPIE Ocean Sens. Monitoring III, 80300D--1.

Liceaga-Correa, M. A., \& Euan-Avila, J. I. (2002). Assessment of coral reef bathymetric mapping using visible Landsat Thematic Mapper data. International Journal of Remote Sensing, 23(1), 3-14.

Lyzenga, D. R. (1978). Passive remote sensing techniques for mapping water depth and bottom features. Applied Optics, 17(3), 379. http://doi.org/10.1364/AO.17.000379

Lyzenga, D. R., Malinas, N. P., \& Tanis, F. J. (2006). Multispectral bathymetry using a simple physically based algorithm. IEEE Transactions on Geoscience and Remote Sensing, 44(8), 2251-2259. http://doi.org/10.1109/TGRS.2006.872909

Paredes, J. M., \& Spero, R. E. (1983). Water depth mapping from passive remote sensing data under a generalized ratio assumption. Applied Optics, 22(8), 1134. http://doi.org/10.1364/AO.22.001134

Stumpf, R. P., Holderied, K., \& Sinclair, M. (2003). Determination of water depth with high-resolution satellite imagery over variable bottom types. Limnology and Oceanography, 48(1part2), 547-556. http://doi.org/10.4319/lo.2003.48.1_part_2.0547

Yuzugullu, O., \& Aksoy, A. (2014). Generation of the bathymetry of a eutrophic shallow lake using WorldView-2 imagery. Journal of Hydroinformatics, 16(1), 50. http://doi.org/10.2166/hydro.2013.133 